\title{
Study and Application Status of Additive Manufacturing of Typical Inorganic Non-metallic Materials
}

\author{
Yun YU ${ }^{1}$, Tingchun SHI ${ }^{*}$, Yonghui MA ${ }^{1}$, Fangfang SUN ${ }^{1}$, Jinde PAN ${ }^{2}$, Yong YANG ${ }^{1}$ \\ ${ }^{1}$ Hangzhou Dianzi University Institute for Biomedical Engineering \& Instrumentation, Hangzhou 310018, China \\ ${ }^{2}$ Zhejiang Institute of Geology and Mineral Resources, Hangzhou 310007, China \\ crossref http://dx.doi.org/10.5755/j01.ms.26.1.18880
}

Received 22 August 2017; accepted 15 October 2018

\begin{abstract}
Additive manufacturing is a rapid manufacturing based on discrete accumulation to achieve prototypes or parts of products. Inorganic non-metallic materials, as one of the three major materials, have incomparable application prospect in medical, aerospace, automotive, construction, arts and crafts, as well as many other fields. In order to rapidly create devices with arbitrarily complex shapes, additive manufacturing of inorganic non-metallic materials is becoming a hot spot of current research. In view of the technical types, materials and other aspects, this article introduced research status and development of additive manufacturing in inorganic non-metallic materials at home and abroad. Several common inorganic non-metallic materials are compared and analyzed, such as $\mathrm{Al}_{2} \mathrm{O}_{3}, \mathrm{Si}_{3} \mathrm{~N}_{4} \mathrm{SiO}_{2}, \mathrm{ZrO}_{2}$, etc. The forming characteristics and the problems of several popular ceramic materials and sand-casting materials are illustrated with emphases. The key problems existed in additive manufacturing forming process of inorganic non-metallic material are pointed out and urgent to be solved at present. Furthermore, the impacts of the material handling process, three dimensional printing (3DP), Selective Laser Sintering(SLS), Selective Laser Melting (SLM) three-dimensional forming processes and post treatment process on the quality and performance of the forming parts are analyzed. Finally, the prospects in SLS of the gem material are put forward.

Keywords: additive manufacturing, inorganic non-metallic materials, material handling process, three-dimensional forming process, post treatment process, 3D printing; selective laser sintering, selective laser melting.
\end{abstract}

\section{INTRODUCTION}

With the development of materials science, the variety of inorganic non-metallic materials are increasing, the current commonly used inorganic non-metallic materials include: ceramics, glass, non-metallic ore, the original sand, cement, semiconductors, etc. In the crystal structure, the inorganic non-metallic crystal structure is far more complex than metal's. It has no free electrons and has ionic bond and mixed bond which are stronger than the metal bond and pure covalent bond. This special high bond energy and high bond strength of chemical bond gives inorganic non-metallic materials many properties including high melting point, high hardness, corrosion resistance, wear resistance, high strength and good oxidation resistance and so forth. Besides, there are other characters, such as the broad electrical conductivity, thermal insulation, light penetration and good piezoelectric and ferroelectric and ferromagnetic [1]. These advantages of inorganic non-metallic materials are irreplaceable for polymer materials and metal materials, so that the application of such materials is becoming more and more important, especially in the architecture, national defense, electronic, medical, casting.

The traditional processing technology of inorganic non-metallic materials has many defects include backward production technology, low level of automation, long production cycle, insufficiently use of materials and so on. The inorganic non-metallicmaterials processing is very difficult to meet production requirements. In order to seek advanced manufacturing technology, both domestic and foreign scholars are constantly exploring. The emergence of additive manufacturing technology exactly makes up and overcomes the shortcomings of traditional processing technology, and brings a new future for the production of inorganic nonmetallic materials. Additive Manufacturing emerged in the late 1980s [1], also known as rapid prototyping technology, which changes the traditional "remove" manufacturing into "increase" manufacturing and which has the development of high efficiency, no mold, shape-forming complex devices, low cost and many other advantages. Its research and application in the field of inorganic nonmetallic materials not only provide a new way for the manufacture of inorganic nonmetallic materials, but also make its new products more competitive in the market.

At present, there are several kinds of common additive manufacturing techniques: Laminated Object Manufacturing (LOM), Stereo Lithography Apparatus (SLA), Fused Deposition Molding (FDM), 3D Printing (3DP), Selective Laser Sintering (SLS), Selective Laser Melting (SLM), etc., among which 3DP, SLS and SLM are commonly used in the production of inorganic nonmetallic materials. Most of the inorganic nonmetallic materials used in additive manufacturing are in the state of slurry and powder. Whether the raw material is well handled is directly related to the quality and performance of the subsequent forming parts, and the state of the raw material also indirectly determines which kind of additive manufacturing technology should be used.

\footnotetext{
* Corresponding author. Tel.: +860571 86919107.

E-mail address: stc@hdu.edu.cn (T. Shi)
} 


\section{THE DEVELOPMENT OF INORGANIC NON-METALLIC MATERIALS USED IN ADDITIVE MANUFACTURING}

\subsection{The development of inorganic non-metallic materials used in 3DP}

Three-dimensional printing (3DP) technology developed by the Massachusetts Institute of Technology, it is an additive manufacturing method that utilizes microjetting technology whose process is similar to the printer. During the process, spray adhesive in the pre-paved powder where it is needed to form a thin layer, and then layer by layer to finally obtain the three-dimensional part $[2,3]$. Most of materials used for three-dimensional printing of the material are in the state of powder, such as metal, ceramics, the original sand, gypsum, cement and other powder, of which these two categories of materials the ceramic and the raw sand are the most commonly used in three dimensional printing.

\subsubsection{DP of forming ceramics}

Ceramic material is a kind of inorganic nonmetal material, which is made of natural or synthetic compounds through the forming and high temperature sintering. It has the advantages of most inorganic non-metallic materials which can be used as structural materials, tool materials and functional materials. At present, ceramic material is irreplaceable in order to meet the demands of people in the following cases: alumina ceramic has high temperature resistance, corrosion resistance, high strength, which can be used as crucible, engine spark plug, thermocouple sleeve, sealing ring and also can be used as a tool and die; silicon nitride ceramic not only has the characteristics of alumina ceramic, but also has self-lubricating properties, which can be used as high temperature bearing and metal cutting tools; silicon carbide ceramic with high temperature, high strength, as well as good thermal conductivity, oxidation resistance, conductivity and high impact toughness, which can be used for rocket nozzle and grinding wheel, abrasive, etc [4]. Bioceramics have good biocompatibility and can be used to make human bones, teeth, tendons, etc. to repair or replace human organs or tissues [4].

\subsubsection{3DP of forming $\mathrm{Al}_{2} \mathrm{O}_{3}$ ceramics}

In 1993, Sachs et al. at first used 3DP method to form ceramics, and then the warm isostatic pressing was carried out to improve the ceramics density, eliminate the intergranular defects, and finally through the high temperature sintering, the ceramic part was obtained. Because the raw materials added $\mathrm{MgO}$ as sintering agent, the density and strength of the final ceramic pieces are higher [5]. J. Grau et al. made the $\mathrm{Al}_{2} \mathrm{O}_{3}$ mold instead of the traditional stone mold by 3DP method for grouting, which has high strength and short drying time [5]. R. Melcher et al. [6] in Erlangen - Nuremberg University of Germany used dextrin as binder and applied 3DP technology to print out the $\mathrm{Al}_{2} \mathrm{O}_{3}$ body, and then calcined at high temperature to obtain $\mathrm{Al}_{2} \mathrm{O}_{3}$ ceramics, finally infiltrate $\mathrm{Cu}_{2} \mathrm{O} / \mathrm{Cu}$ alloy without pressure at high temperature, the final ceramic metal composite was formed, which is shown in Fig. 1.The surface of the formed specimen is rough, and its volume contraction reaches as high as $44.2 \%$ after high temperature sintering.

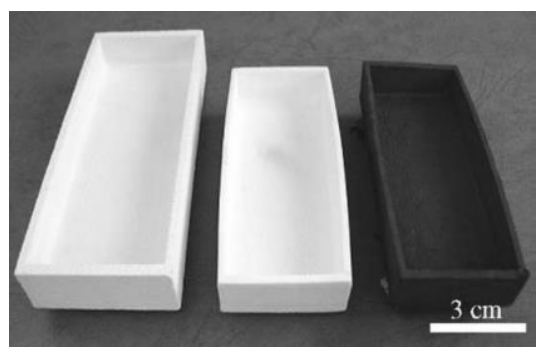

Fig. 1. Formed alumina green body (left), sintered preform (middle), infiltrated crucible (right). Reprinted with permission from [6]. Copyright (C) 2006 Elsevier B.V.

In 2015, Yao et al [7] of State Key Laboratory of High Performance Ceramics and Super Fine Structures, Shanghai Institute of Ceramics, Chinese Academy of Sciences used coarse aluminum powder as raw material to forming with the 3D printing technology. Nearly zero shrinkage (shrinkage at $1 \%-2 \%$ ) of $\mathrm{Al}_{2} \mathrm{O}_{3}$ porous ceramic was made at high temperature sintering under aerobic conditions. As shown in Fig. 2.

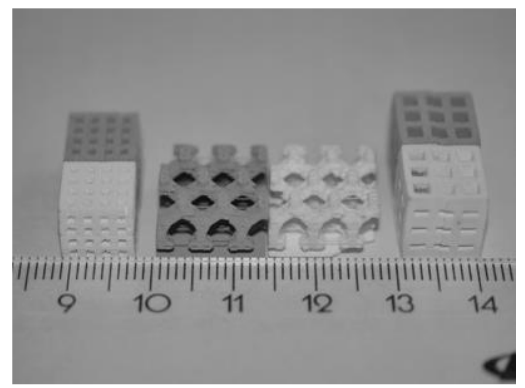

Fig. 2. Printed ceramic body (black) and sintered products (white). Reprinted with permission from [7]. Copyright (C) 2015 Elsevier B.V.

\subsubsection{3DP of forming $\mathrm{Si}_{3} \mathrm{~N}_{4}$ ceramic}

Weng Zuhai, Zeng Qingfen, et al of China's Northwestern Polytechnical University, used silica gel as the starting material and dextrin as binder. The porous silica body was prepared by three-dimensional printing (3DP), then through the nitrogen $\left(\mathrm{N}_{2}\right)$ environment sintered to obtain high porosity silicon nitride $\left(\mathrm{Si}_{3} \mathrm{~N}_{4}\right)$ ceramics. The bending strength of the silicon nitride ceramic highest at $(5.1 \pm 0.3) \mathrm{MPa}$, and the porosity is $(74.3 \pm 0.6) \%$, and the linear shrinkage less than $2 \%$ in the process of reactive sintering [8]. B.Cappi et al [9]. at Germany Aachen University of Technology used silicon nitride suspensions as the raw materials, the first 3DP was adopted to forming this materials, then sintered at high temperature with yttrium aluminum garnet (YAG) as sintering agent. Finally, ceramic specimen was obtained [9]. Its density was $3.18 \mathrm{~g} / \mathrm{cm}^{3}$, Vickers hardness (HV 0.2) was 17, the fracture toughness (KIC) was 4.4 MPa. $\mathrm{m}^{0.5}$, as shown in Fig. 3.

\subsubsection{3DP of forming composite ceramic}

In 1999, two zirconia and alumina composite ceramics were prepared by M. and Mott, etc. [10], used inkjet printing technology (3DP) and high temperature sintering. In 2001, Jooho Moon et al. [2] of the Massachusetts Institute of Technology adopted furan resin as binder, forming 
45-105um size of carbon particles, then pressureless reaction infiltration on the formed body under the $1450^{\circ} \mathrm{N}_{2}$ environment, and ultimately $\mathrm{SiC}-\mathrm{Si}$ composite ceramic was got, as shown in Fig. 4.

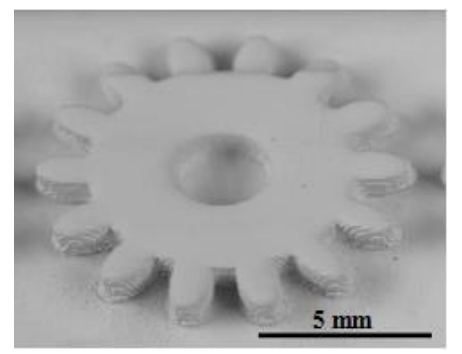

Fig. 3. Printed $\mathrm{Si}_{3} \mathrm{~N}_{4}$-gearwheel. Reprinted with permission from [9]. Copyright (C) 2008 Elsevier B.V.

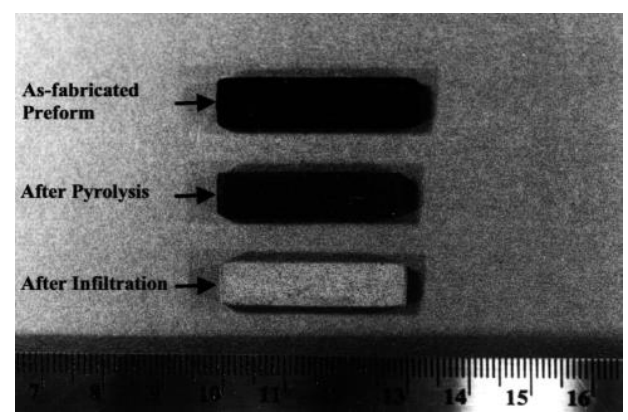

Fig. 4. d3D printed cuboid (up), pyrolyzed sample(middle) reactive-infiltrated composite ceramic of $\mathrm{Si}_{3} \mathrm{~N}_{4}$ $\mathrm{SiC}$ (down). Reprinted with permission from [2]. Copyright (C) 2001 Elsevier B.V.

In June 2012, the $\mathrm{Si}_{3} \mathrm{~N}_{4}-\mathrm{SiC}$ composite ceramics was fabricated by the method of three-dimensional printing and chemical vapor infiltration in Northwestern Polytechnical University [11]. In 2013, Z. Fu et al [12] of German El Langen-Nuremberg University used the mixture of silicon, silicon carbide and dextrin powder as the base material. The body was printed out with 3DP technique and it was penetrated by the resin to stabilize its shape, then thermal decompose resin in the $\mathrm{N}_{2}$ environment. The body was infiltrated by silicon powder, and sintered in high temperature, finally SiSiC composite ceramic was obtained. Fig. 5 is a complex structure of the prepared specimen. The proportion of $\mathrm{Si}$ and $\mathrm{SiC}$ content in base material is different, so the density, porosity, bending strength and fracture toughness of specimen are different.
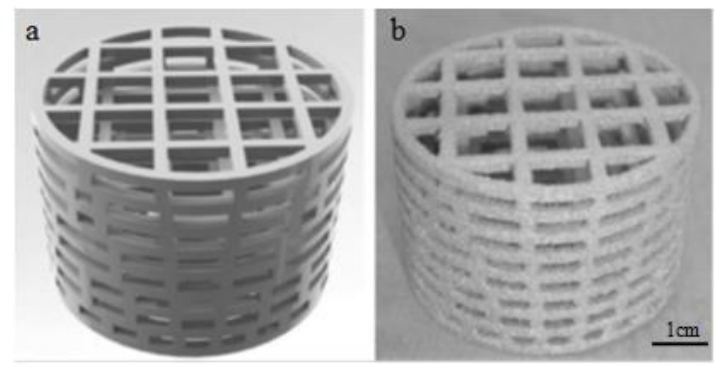

Fig. 5. a-CAD model; b-SiSiC part was obtained by reactive infiltration of formed billet. Reprinted with permission from [12]. Copyright () 2013 Elsevier B.V.

The study found that the density of specimen is about $2.5 \mathrm{~g} / \mathrm{cm}^{3}$, he porosity is less than $8.2 \%$, flexural strength between $65 \mathrm{MPa}$ and $233 \mathrm{MPa}$, the fracture toughness about $1.1-2.7 \mathrm{MPa} \cdot \mathrm{m}^{0.5}$.

From the above research, it is shown that the ceramic porcelain prepared by three-dimensional printing has a larger porosity and a higher density, and it need subsequent sintering and liquid phase infiltration to obtain a higher quality ceramic device. In addition, the precision of the device is strictly limited by the nozzle size, and the nozzle is easily blocked which needs regular maintenance.

\subsubsection{DP of forming sand type}

Sand casting plays a very important role in the casting industry, and the application of three-dimensional printing technology, which can form any complex shape parts in sand casting has brought significant changes.

Yang Weidong et al. [13-16] of China's Tsinghua University, have developed the Patternless casting manufacturing technology (PCM), which is based on the three-dimensional printing technology of spraying binder. According to the interface contour information, the binder and catalyst were sprayed out from dual nozzle at the same time. The cross-linking between them can make a coating which can be used to pour the sand. $70 / 140$ resin sand in the traditional casting process were selected as material of patternless casting manufacturing technology. Through the comprehensive consideration of the hotspots of PCM technology, it can be seen that the furan resin binder and the toluene sulfuric acid catalyst have good physical and chemical properties. Moldless mold manufacturing technology is more suitable for the manufacture of large and medium-sized castings. Fig. 6 shows the impeller made by this technology [17]. Of course, although the mold made by moldless manufacturing technology has low cost, high strength and other advantages, its surface quality requirements have yet to be improved.

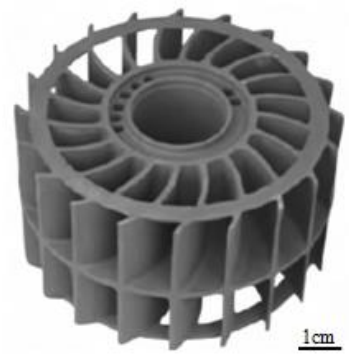

Fig. 6. Impeller was fabricated by patternless casting manufacturing. Reprinted with permission from [17]. Copyright (C) 2013 Elsevier B.V.

The technology, which combined 3DP and casting in abroad can be presented as follows: the direct shell casting (DSPC) process in the United States, GS (Generis'RP Systems) process the German, ZCorp's ZCast process and ExOne's ProMetal RCT process. DSPC process is similar to China's mold-free manufacturing process, which is based on the Massachusetts Institute of Technology 3DP patent which developed by a rapid prototyping casting process [18]. By using 75-150 um ceramic powder, it can form a better surface quality and it is suitable for manufacturing medium and small castings [18]. The first step of GS process is to pave sand and spray the resin into the sand bed with multi-nozzle cluster. Then the catalyst was sprayed by a 
nozzle according to the contour path, and the glue reaction of the catalyst occurred, which made the layers solidified into forming. The size of the process sandbox is generally large, suitable for casting large and medium-sized castings. But the formed castings are surrounded by resin sand, so the sand is difficult to clean when sand mold was taken and special processing procedures are required. It also affects the accuracy and surface quality of the sand. ZCast process is mainly used to manufacture non-ferrous metal sand, the thickness of the wall of the molded shell can reach $12 \mathrm{~mm}$. The material selected for this casting technique typically comprises a mixture of plastic, foundry sand, and the remainder of the mixture. In addition, in order to reduce the cost of printing, the standard ZP14 powder is often used as a printing material. ProMetal RCT process usually choose resin sand as a forming material, and synthetic sand, silica sand or other casting media as a sand material. The molded castings need not post-special treatment and it can be directly used to pouring after clean the sand around the castings. It is generally used to shape large casting [18].

Most of sand molds formed by 3DP are high resin content, poor mold permeability and low accuracy. And there is a step effect. It is generally suitable for small quantities of a single casting production rather than large quantities of industrial production. This is because the 3DPbased casting sand process whose efficiency and quality are a pair of contradictory. High efficiency will inevitably enlarge the "step effect." In order to achieve massproduction of sand molds with 3DP, it needs a variety of late processing technology to solve this problem.

The same shortcoming of 3DP forming ceramic and sand type is that the forming accuracy is not high. It contains a lot of pores. However, this shortcoming is also an advantage in some situation, such as the application in biological tissue engineering stent, bone tissue and dental restorations [19-23]. Besides, for the construction industry which is not demanding for high accuracy [24], 3DP forming process will bring it a new look.

\subsubsection{Development status of SLS forming of inorganic nonmetallic materials}

SLS was proposed by Carl Ckard of the University of Texas at Austin in 1989 [25]. Using a pre-set powder, laser selectively sieves the solid powder and superimposes the sintered cured layers to form the desired shape. According to the mechanism of powder forming, SLS is divided into four types: solid phase sintering, liquid sintering part melting, all melting, chemical induction and combination [25]. Depending on whether the binder is used in the forming process, SLS is divided into two types: the addition of the binder and the without addition of the binder. The mixture made by SLS, which is added binder, can be divided into two types: one is the slurry, the other is the powder material. Both of them are made from the powder-like base material and binder composition. The slurry needs to be dried before selective laser sintering printing, while the powder material can be directly selected for selective laser sintering. The body printed by SLS needs debinding to remove the binder and impregnation of a material or isostatic pressing to improve the density. The mixture is composed of two kinds of powdery materials, which have low melting point and high melting point. High melting point material is the material to be formed. During the SLS process, the appropriate laser energy melts the low melting powder material and cannot melt high melting powder material, so that low melting point powder material bonds high melting point powder material to form it.

There are many types of SLS formed materials, which are covered in the polymer materials, metal materials and inorganic non-metallic materials. In inorganic nonmetallic fields, SLS forming materials are commonly used as ceramic materials and coated sand. Wuhan Huazhong University of Science and Technology, Tsinghua University in Beijing, the University of Leuven in Belgium, the University of Texas at Austin, and other research institutions have a deeper study about it. The study of the ceramic material SLS molding mainly concentrated on the alumina ceramic $\left(\mathrm{Al}_{2} \mathrm{O}_{3}\right)$, zirconia ceramic $\left(\mathrm{ZrO}_{2}\right)$, silicon carbide ( $\mathrm{SiC})$ and some composite ceramics [26-29].

Khuram Shahzad et al. [30], University of Leuven, Belgium, coated the polyamide (PA) as a binder on the surface of the alumina powder particles by a dissolvingprecipitation method to prepare a powder base and then the laser selectively sintered to form the powder base. Finally, after hot isostatic pressing, infiltration of silica sol, degreasing and high temperature sintering treatment, the $68 \%$ relative density alumina ceramic was obtained. Yusheng team of Huazhong University of Science and Technology made composite powder, which contains organic binder PVA and ER06 $\mathrm{Al}_{2} \mathrm{O}_{3}$, by using the technique of a combination of film and mixed preparation. After selective laser sintering, compression molding, degreasing and high temperature sintering of the mixed preparation, ceramic parts whose relative density greater than $92 \%$ was obtained on its self-developed HRPSIV(Hua rapid prototyping system-IV) forming machine [31], as shown in Fig. 7.

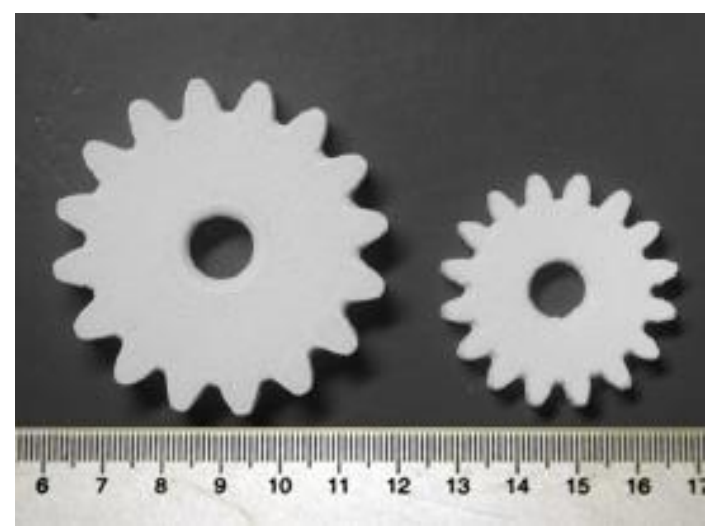

Fig. 7. Alumina green gear manufactured by SLS (left) and the alumina gear densified by CIP and process (right). Reprinted with permission from [31]. Copyright (C) 2014 Elsevier B.V.

Hwa-Hsing Tang [32,33] of Taipei University of Science and Technology used fully hydrolyzed polyethylene glycol as a binder. Based on colloidal science principle, a good dispersion $\mathrm{Al}_{2} \mathrm{O}_{3}$ ceramic slurry was configured, which sintered layer by layer under the action of the laser, and the three-dimensional solid ceramic parison was accumulated. Then the parison passed through degreasing and sintering at high temperature. The average relative density of the final ceramic parts reached $98 \%$. 
However, the method of forming ceramic parts is very inefficient because the slow drying of the upper forming layer, which must be completed before the next layer begins to form during the forming process. So the part forming rate is very slow and difficult to satisfy the future demand for mass and efficient manufacturing of ceramic parts, which is also a common drawback of slurry-based SLS technology.

In 2007, Ph. Bertrand et al. [29] used the SLS process to print a zirconia blank with a density of $56 \%$. Khuram Shahzad et al. [34] of the University of Leuven in Belgium also studied the preparation of zirconia ceramics for SLS. They prepared spherical polypropylene-zirconia composite powders by heat-to-phase separation by using a SLS process to print green bodies with a relative density of $36 \%$. And the $92 \%$ density zirconia oxide ceramics were prepared by pressure permeation of zirconia suspension, hot isostatic pressing and high temperature sintering. In order to maintain the shape of the green body and further improve the density of the green body during the high temperature sintering process, it is necessary to add a certain amount of $\mathrm{Y}_{2} \mathrm{O}_{3}$. Peugeamedu et al. [26] of the University of Pennsylvania found that the yttrium content in zirconia had a certain effect on the quality of the shaped parts. When the content of yttrium oxide in zirconium oxide is high, the surface quality of the molded parts is poor. There are cracks and holes caused a low density; yttrium oxide content is low, which have fine microstructure and high density.

In 2006, Ren Yusong et al. [35] of Nantong University in China, achieved nano-SiC forming based on selective laser sintering process. The sintered nano-SiC microstructure in the sintering layer was analyzed by X-ray diffraction, scanning electron microscopy, meanwhile the laser sintering process and process the effects of parameters are discussed. The results show that the sintered shape of $\mathrm{SiC}$ ceramic block can be realized by selective laser sintering process. The internal structure of the sintered part is nanostructured, and the grain size of the material is not big. However, the decomposition of $\mathrm{SiC}$ in the sintering process produces nano Si and C. Xiong Huaping et al. [36] of Nanchang University of Aeronautics and Astronautics studied the effect of binder on the dimensional accuracy and mechanical properties of SLS-shaped SiC ceramics. It was found that SLS forming dimension accuracy was $98.42 \%$ by using epoxy resin as binder. The use of epoxy resin and $\mathrm{NH}_{4} \mathrm{H}_{2} \mathrm{PO}_{4}$ as a binder maintained the dimensional accuracy of the body, and the tensile strength and bending strength are higher than prefabricated body, which used epoxy resin alone as a binder. After that, they tried to use nylon 6 and $\mathrm{NH}_{4} \mathrm{H}_{2} \mathrm{PO}_{4}$ as the binder, and the final $\mathrm{SiC}$ ceramics were improved in dimensional accuracy and mechanical properties. The effect of process parameters on the sintering quality of $\mathrm{Al}_{2} \mathrm{O}_{3} / \mathrm{SiO}_{2} / \mathrm{ZrO}_{2}$ composite ceramics during the SLS forming process was studied by orthogonal test method [37]. Shi Yusheng team of Huazhong University of Science and Technology studied SLS forming $\mathrm{Al}_{2} \mathrm{O}_{3} / \mathrm{SiO}_{2}$ composite ceramics. The results show that the strength and density of the sintered parts increased with the increase of the $\mathrm{SiO}_{2}$ content. When the $\mathrm{SiO}_{2}$ content fraction reaches $20 \%$, the tensile strength of the sintered material is $45 \mathrm{MPa}$ at $1450^{\circ}$ for $45 \mathrm{~h}$, and the density is $2.35 \times 103 \mathrm{~kg} / \mathrm{m}^{3}$.

The study found that SLS forming ceramic technology generally includes four processes: the preparation of materials, laser selective sintering forming, isostatic pressing, infiltration treatment and high temperature sintering. The asymmetric pieces are deformed obviously in the process of isostatic pressing and high temperature sintering process. It is also a common problem on the SLS forming ceramic that needs to improve on late research [38]. While molds formed with coated sand, silica sand and other materials, which based on the SLS process, do not need isostatic pressing and high temperature sintering treatment. The formed ceramic has high precision. This technology plays a huge role in the sand casting industry [39-41]. In addition, SLS process, which is used in bone and stent preparation with hydroxyapatite, $\beta$-tricalcium phosphate and other materials artificial, has also been extensively studied in the field of biomedical engineering [42-44].

\subsubsection{Development of inorganic nonmetallic materials SLM forming}

The SLM evolved on the basis of SLS, which was designed by laminating the solid-state solid powder by laser. It was originally proposed by the German Fraunhofer Laser Institute in 1995 [45, 46]. Unlike SLS, SLM does not need to add binder during the forming process but is shaped by melt-curing of the powder. It is conveniently to control the porosity and pore shape and to form porous parts with complex internal structure [47]. The SLM process is mainly used for the forming of metal or alloy parts, and is less used for ceramic forming belong to inorganic nonmetallic materials [45].

Shishkovsky of the Lebedev Institute of Physics in Russia and Yadroitsev of the DIPI laboratory in France [48] used the SLM process to print the $\mathrm{ZrO}_{2}-\mathrm{Y}_{2} \mathrm{O}_{3}$ composite powder on the Phenix PM-100 machine in 2007. Finally, $\mathrm{ZrO}_{2}$ ceramics with relatively low porosity and relatively high geometric accuracy were obtained, but it still has pores and cracks, as shown in Fig. 8. Hagedom and YvesChristian [49] of Fraunhofer Institute of Laser Hagedom, who used the SLM process directly to produce almost $100 \%$ density of $\mathrm{Al}_{2} \mathrm{O}_{3}-\mathrm{ZrO}_{2}$ ceramic parts. In the study, although the forming powder was preheated at a temperature higher than $1600{ }^{\circ} \mathrm{C}$, the final printed ceramic was still cracked.

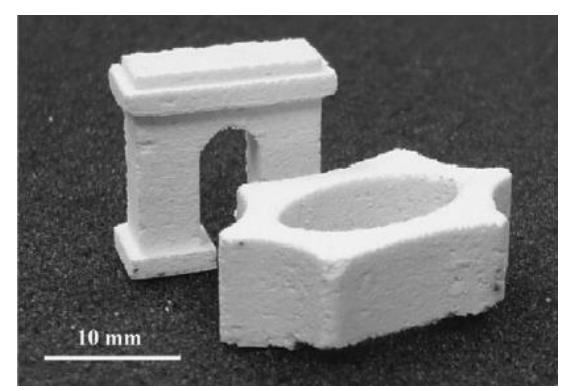

Fig. 8. $\mathrm{ZrO}_{2}$ samples were produced by SLM process (Phenix PM100 machine). Reprinted with permission from [48]. Copyright (C) 2007 Elsevier B.V.

During the forming process, the cracks often occur because of the greater temperature and stress changes [50-52]. In order to reduce the occurrence of cracks, SLM forming powder preheating process is very important. Dr. Wilkes [46] conducted an experimental study in this area. The SLM forming ceramic process have been also 
studied in Huazhong University of Science and Technology and the University of Leuven, Belgium. Although the study found that the SLM process can form a high density specimen, there are inevitable cracks in the current ceramic which make the SLM process rarely used in ceramics [53].

\section{FACTORS AFFECTING THE PRODUCTION OF INORGANIC NONMETALLIC MATERIALS}

In the whole process of inorganic non-metallic materials, there are many factors that will directly affect the quality and performance of the forming parts. The main factors that affect the rapid formation of inorganic nonmetallic materials are: material processing technology, 3DP, SLS, SLM Three-dimensional forming process, the three major aspects of post-processing technology. In addition, the hardware situation of the material manufacturing machine will also affect the quality and performance of forming parts, but there's no discussion here. The detailed exposition on how these three factors influence the quality and performance of the forming parts as follows.

\subsection{Material handling process}

The forming material is mainly composed of base material, binder, additive and others, in which the binder plays an important role in shaping the inorganic nonmetallic material, and its selection depends on the performance of the substrate to be printed. The liquid adhesive used in 3DP process can be divided into three types. One is the liquid that cannot bond itself, another is the liquid that will react with the powder and last one is the liquid that can partly bond. Chloroform ethanol, some liquid resin, water-based adhesives are often used [54-56]; For the SLS, SLM process, the use of the binder are mostly powder, mainly divided into organic and inorganic two categories. Polymethacrylic resin (PMMA), nylon, epoxy resin, Dihydrogen phosphate $\left(\mathrm{NH}_{4} \mathrm{H}_{2} \mathrm{PO}_{4}\right)$ and so on are often used [44, 57-58]. Among the many binders, the choice of binder with the base material can achieve the purpose of rapid prototyping. In the 3DP process, some powder binder, such as polyvinyl alcohol, cellulose, maltodextrin, can be added to strengthen the forming strength of the substrate powder.

In contrast, the particle size and morphology of the powder have a deep influence on the quality and performance of the forming part. The particles with small particle size and irregular morphology can provide a strong van der Waals force, but its rollability is poor. And they are easy to splash during the printing process, which will lead nozzle clogging in the 3DP process. As for SLS, SLM, this kind of particles will lead uneven spread powder and cracks in every layer in laser sintering. Large spherical particles have better rollability, but they will affect the print accuracy of parts [59]. The powder particle size of the forming different materials depends on the material itself and the type of printer type. Typically, it is better that the size of the powder particles is different. Because the small particle size particles can be filled in large particles during the printing process, which increases the density of pieces. The shape of the powder is better to closer to the ball. In order to prevent the formation of piezoelectric ceramic transducer (PZT) cracks in the 3DP forming, Song and others of the University of Brunel, England [60] selected PZT with a diameter of $2 \mu \mathrm{m}$ as a forming powder. Tang Chengcheng of Zhejiang University of Technology [61] who used $\mathrm{Al}_{2} \mathrm{O}_{3}$ and PA12 powder materials to carry out SLS experiments and obtained $\mathrm{Al}_{2} \mathrm{O}_{3}$ ceramic specimen. During the experiment, $\mathrm{Al}_{2} \mathrm{O}_{3} / \mathrm{PA} 12$ composite powders with particle size distribution of $50 \sim 200 \mu \mathrm{m}$ were prepared by screw extrusion granulation and cold crushing. The morphology of the prepared powder particles was analyzed in detail. Fig. $9 \mathrm{a}$ and $\mathrm{b}$ shows that $\mathrm{Al}_{2} \mathrm{O}_{3}$ particles can be better dispersed in the PA12 matrix, there is no obvious agglomeration phenomenon. Fig. $9 \mathrm{c}$ and d shows that the powder particles are irregular in shape, which conducive to sintering densification but not conducive to mechanical powder.

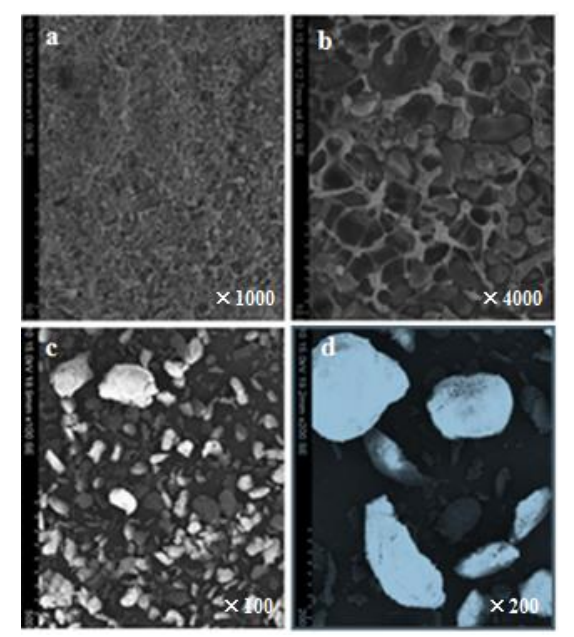

Fig. 9. Fractured SEM morphology: a, b-particle; c, $\mathrm{d}$-composite powder. Reprinted with permission from [61]. Copyright @ 2015 Chine Plastic Industry

In the process of making inorganic nonmetallic materials for 3DP, SLS and SLM, it is important to prepare the powder material before the preparation, and the preparation of the powder material to be shaped is determined by the material preparation process. Today, 3DP, SLS, SLM powder material preparation process can be divided into mechanical mixing method, coating method and twin screw extrusion crushing, in which the coating method is divided into spray granulation and solvent precipitation method [62, 63]. Mechanical mixing process is simple, and different powders are difficult to mix evenly, so segregation phenomenon often occurred in the process of powder. The coating process is complex, but it can make the binder bone well on the base powder particles, so that the shape of prepared powder is close to a ball and good mobility of the powder is conducive to powder; The shape of the powder particles produced by the twin-screw extrusion pulverization method is extremely irregular and is not conducive to the improvement of the precision of the powder and the forming parts. Generally, the coating method is superior to the mechanical mixing method, the mechanical mixing method is superior to the twin-screw extrusion pulverization method. In order to obtain a more excellent molding material, the researchers usually combine the coating method and the mechanical mixing method $[64,65]$. 
In general, the material handling process is a complex process that is not only related to the material preparation process, but also related to the formulation of the material. For example, dispersants are often added to the powder to prevent the powder particles from agglomeration, which is beneficial for spreading powder. The most suitable material formula of different base materials is different. This is the research focus of rapid formation of inorganic non-metallic materials in the future.

\subsection{DP, SLS, SLM three-dimensional forming process}

In the process of printing non-metallic materials in 3DP process, the forming process parameters which affect the quality and performance of the parts are the diameter of the nozzle, the extrusion speed, the extrusion pressure, the scanning speed, the thickness of the layer. the middle delay time and construction direction and so on [66-68]. Liu Jiyuan of Shanghai Electric Power Institute [69] who focused on how the nozzle diameter, extrusion speed, extrusion pressure, scanning speed and the layer thickness influence the quality of forming parts. The experiment make a conclusion that the ideal ceramic part can be printed with the extrusion head length of $5 \mathrm{~mm}$, an initial die diameter of $0.6 \mathrm{~mm}$, an extrusion pressure of $4 \mathrm{~kg} / \mathrm{cm}^{2}$, a scanning speed of $20 \mathrm{~mm} / \mathrm{s}$ and a thickness of $0.5 \mathrm{~mm}$. Mitra AsadiEydivand et al. [70] of the University of Malaya studied the influence of layer thickness, the delay time in spreading a new layer and build orientation. The optimum process parameters are shown in Table 1. Table 1 shows the optimum process parameters of the two samples. The compressive strength of the two samples is very similar, but the total porosity of the Young's modulus with the thickness of $89 \mu \mathrm{m}$ is less than those with the thickness of $114 \mu \mathrm{m}$. So the former is more suitable for bone tissue engineering stent.

The diameter of the nozzle in the 3DP process has a large influence on the porosity and surface roughness of the forming part [71, 72]. The larger diameter of the nozzle is, the larger porosity of the forming part is and the coarser the surface is and vice versa. It is difficult to produce a smaller diameter nozzle practically. Even if a small diameter nozzle is produced, it will also cause jamming of the material, which results in a larger porosity of the inorganic nonmetallic device prepared by the 3DP process. Although the formed body is post-treated, the density of the final piece is not high. So the process is not capable of producing fully dense inorganic non-metallic devices currently.

In the SLS process, low melting point of the polymer material as a binder, preheating temperature is generally lower than the high-molecular material melting point of 2 to 3 degrees [77]. Wang Wei of Institute of Mechanical and Electrical Engineering, Shenyang of Institute of Aeronautical Engineering and Yang Guang of Shenyang Institute of Automation, Chinese Academy of Sciences [77] studied the warping deformation of the selective laser sintering rapid prototyping parts to find out the root cause of warping deformation. They found how the parameters of laser scanning speed, laser power, preheating temperature and others influence the warping deformation. Table 2 shows the different deformation produced at different preheating temperatures. It is found that the preheating temperature of $130{ }^{\circ} \mathrm{C}$ is relatively good.

N. Raghunath et al. [78] of the Department of Mechanical Engineering in New Delhi Institute of Technology, in order to reduce the shrinkage of components to improve its accuracy, they used the Taguchi method and variance analysis to obtain the optimal laser power, scanning speed, scanning spacing, scanning layer thickness and other parameters.

And they also analyzed which parameters are more affected by the contraction of X, Y and Z. Typically, in the SLS, SLM printing process, to the best value of the laser power, scanning speed, scanning distance, scanning layer thickness and other parameters are often obtained by the orthogonal experiment method.

The degree of influence of different process parameters on contraction, relative density, bending strength and others of the body can be obtained by statistical variance analysis method.

China Huazhong University of Science and Technology and Foreign Belgium Leuven University are two major research institutions of SLS, SLM technology. Liu Kai of Huazhong University of Science and Technology, who described the influence degree of the laser power, scanning speed, scanning distance, scanning layer thickness and other parameters on the relative density, shrinkage, bending strength of forming parts in detail in the study of SLS forming $\mathrm{Al}_{2} \mathrm{O}_{3}$ ceramic technology. As shown in Fig. 10.

Table 1. The optimum fabricated scaffolds in terms of compressive strength [70]

\begin{tabular}{|c|c|c|c|c|c|c|c|}
\hline $\begin{array}{c}\text { Layer thickness, } \\
\mu \mathrm{m}\end{array}$ & $\begin{array}{c}\text { Delay } \\
\text { time, } \mathrm{ms}\end{array}$ & $\begin{array}{c}\text { Degree of } \\
\text { anisotropy }\end{array}$ & $\begin{array}{c}\text { Compressive } \\
\text { strength, MPa }\end{array}$ & $\begin{array}{c}\text { Young's } \\
\text { modulus, Pa }\end{array}$ & $\begin{array}{c}\text { Close } \\
\text { porosity }\end{array}$ & $\begin{array}{c}\text { Open } \\
\text { porosity }\end{array}$ & $\begin{array}{c}\text { Total porosity, } \\
\%\end{array}$ \\
\hline 89 & 300 & 0.43 & 0.75 & 47.15 & 0.29 & 67.62 & 67.71 \\
\hline 114 & 300 & 0.64 & 0.76 & 46.08 & 0.73 & 63.33 & 63.60 \\
\hline
\end{tabular}

Table 2. Different preheating temperatures cause different warping deformations [76]

\begin{tabular}{|c|c|c|c|c|c|}
\hline \multirow{2}{*}{$\begin{array}{l}\text { Preheating } \\
\text { temperature, }{ }^{\circ} \mathrm{C}\end{array}$} & \multicolumn{3}{|c|}{ Warping deformation, mm } & $\begin{array}{c}\text { Warping deformation } \\
\text { rate, } \%\end{array}$ \\
\hline & group 1 & group 2 & group 3 & average & 11.2 \\
\hline 116 & 1.10 & 1.00 & 1.26 & 1.12 & 6.9 \\
\hline 119 & 0.56 & 0.70 & 0.82 & 0.69 & 5.5 \\
\hline 122 & 0.44 & 0.42 & 0.80 & 0.55 & 5.4 \\
\hline 125 & 0.38 & 0.44 & 0.80 & 0.54 & 1.3 \\
\hline 128 & 0.08 & 0.14 & 0.18 & 0.13 & 0.7 \\
\hline 131 & 0.10 & 0.10 & 0.00 & 0.07 & 0.6 \\
\hline 134 & 0.08 & 0.00 & 0.10 & 0.06 & \\
\hline
\end{tabular}



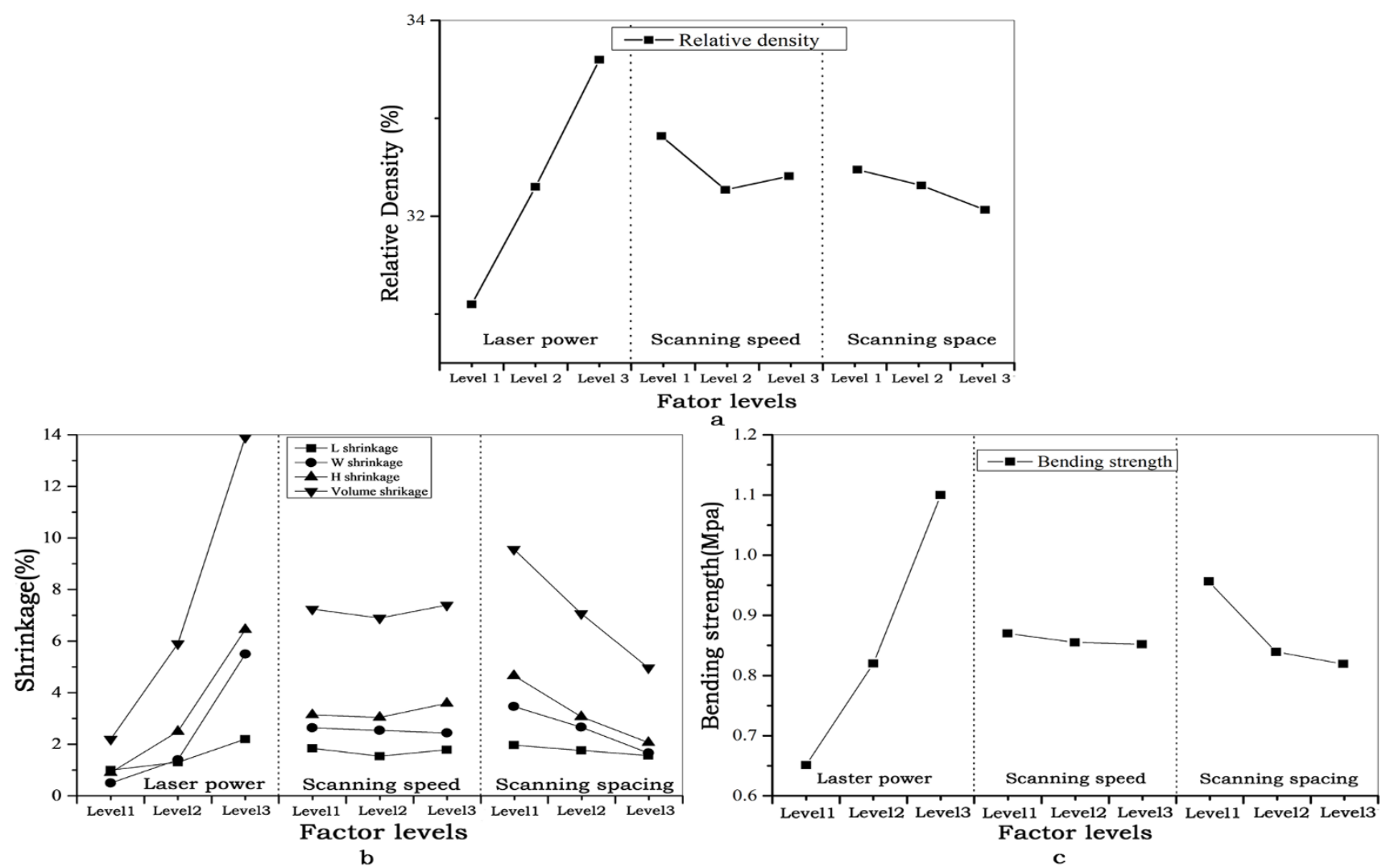

Fig. 10. Average effect of each laser sintering factor upon the a relative density $\mathbf{b}$ shrinkage $\mathbf{c}$ bending strength of the ceramic samples during the SLS processing [31]

It shows that the laser power and scanning distance have a great influence on the performance of the formed specimen, and the scanning speed has no obvious effect on the performance of the forming specimen. So far, although there are a lot of studies on the parameters of inorganic nonmetallic materials in 3DP, SLS, SLM printing process, no mathematical model, which obtains the optimum parameters, can match one class of inorganic non-metallic materials. As for Inorganic non-metallic materials such as ceramic, orthogonal experimental method is used to study the optimal process parameters for different additive manufacturing of ceramic. The process is cumbersome, this special problem is one of the important study directions of the process parameter in 3DP, SLS, SLM printing process an in the future.

\subsection{Post-processing process}

The formed inorganic non-metallic materials in the material manufacturing machine often need to be postprocessed to get the required pieces, especially ceramic materials. The main post-processes include the impregnation, isostatic pressing, high temperature sintering. Its main functions are to improve the density, surface roughness, compressive strength, bending strength and other properties of final pieces. For the forming inorganic non-metallic body, it is generally desirable to combine one or more post-treatment processes.

The impregnation is based on the porous media impregnation theory, which is impregnated into the pores of the medium by capillary force [78]. It is mainly intended to maintain the shape and dimensional accuracy of the preforms of the inorganic nonmetallic materials. Especially in the SLS rapid prototyping process of ceramic materials, in which the binder is removed and the billet is prone to scatter and collapse.

Infiltration is generally divided into natural infiltration, vacuum infiltration and pressure infiltration, commonly used infiltration of silica sol, alumina sol, what Isostatic pressing technology is to place the product in a closed container, through the pressure medium, apply uniform pressure to the product to improve product density [79]. According to the different temperature during the pressure process, the isostatic pressing is divided into cold isostatic pressing and hot isostatic pressing. Cold isostatic pressing is the isostatic pressing method to suppress the product at room temperature to achieve densification. Hot isostatic pressing refers to a special dense isostatic pressing method for pressing and sintering products under high temperature and high pressure.

High temperature sintering is generally applied in the ceramic rapid prototyping process. The 3DP, SLS formed ceramic beads are calcined in the boiling furnace at high temperature to improve the strength and density of the final parts. The sintering process can be divided into three stages without obvious boundaries. One is the contact bonding stage, the second is the sintering neck growth stage, the third is the pore closure, spheroidization and narrowing stage $[80,81-83]$. In the high temperature sintering process, the sintering temperature and sintering time control is essential for different ceramic materials. These two parameters values are determined by the physical properties of materials. 
The effects of infiltration, hot isostatic pressing (HIP) and high temperature sintering on the properties of the final forming parts were studied in detail in the process of forming $\mathrm{Al}_{2} \mathrm{O}_{3}$ or $\mathrm{ZrO}_{2}$ ceramics by the Khuram Shahzada et al. [34, 84-86]. Initially, the bulk density of $\mathrm{Al}_{2} \mathrm{O}_{3}$ or $\mathrm{ZrO}_{2}$ ceramic is about $36 \%$, but the density of the final ceramic member becomes $89 \%$ after the pressure infiltration of alumina or zirconia suspension, hot isostatic pressing and high temperature sintering. The experimental data are shown in Table 3. As can be seen from the table below, the density of SLS forming body increased $2 \%$ by high temperature treatment. The density increased $27 \%$ by both pressure penetration and high temperature sintering treatment. The density increased $52 \%$ by the hot isostatic pressing and high temperature sintering treatment. The density increased $51 \%$ by pressure penetration, hot isostatic pressing, high temperature sintering treatment. The pressure penetration can prevent the collapse of the body when the body collapsed, so to obtain high-density of $\mathrm{Al}_{2} \mathrm{O}_{3}$ or $\mathrm{ZrO}_{2}$ ceramics a combination of three post-processing methods is often used.

In general, due to the performance of powder materials and other reasons, the density and strength of most the inorganic nonmetallic materials forming green body are not high, so the post-treatment process is very necessary. And infiltration, isostatic, high temperature sintering as a commonly used means of post-processing technology have been widely used, especially in the ceramic after the production process.

\section{PROSPECTS FOR THE MANUFACTURE OF GEMSTONE MATERIALS}

Gemstone materials are inorganic non-metallic materials in the non-metallic mineral category. It generally has bright color, special and beautiful patterns, uniform structure, strong refractive index, hardness, stable chemical composition, which is often used as collection, wearing and decoration. At present, different shapes of gemstones are finished by cutting, carving and other processes. In the cutting, carving process will produce some small gem waste. In order to make gem stone waste into treasure, the additive manufacturing of gem material is necessary. In addition, the material additive manufacturing technology can also be made high-complex structure of gem finished products which cannot be made by current processing technology.

After drawing on the technical characteristics of inorganic non-metallic materials, the SLS is used as the technology for the forming materials. At first stage, whether the gemstone material can be shaped lies in the preparation of the material. First, the gem stone scraped into a certain size of the particles, and then mixed with the ball mill or the adhesive coated on the surface of the gem powder particles. In order to prevent the agglomeration of particles, the mixture can be appropriate to add some dispersant, or the like, and finally a mixed powder to be formed is prepared. Put the mixed powder into the SLS forming machine for three-dimensional printing, through continuous experiments to find a set of the best process parameters to get the best gem stone billets. Fig. 11 shows the use of gemstone powder forming bracelet body, from Fig. 11 can be seen that the forming effect is very good and gem stone 3D rapid prototyping is feasible.

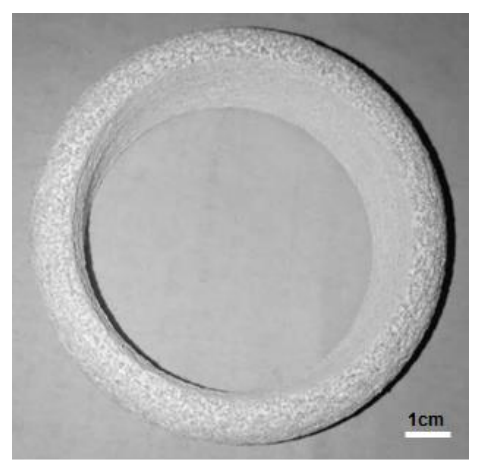

Fig. 11. Selective laser sintering jade powder to form bracelet green body

Although the shape of the gemstone material had realized, but the formed gem is very rough and light. It has low density, low compressive strength, and it contains a small part of the external composition and so on. Further research is needed to improve the quality of the final pieces, to make the final pieces tend to be natural gem texture.

\section{CONCLUSIONS}

This paper elaborated the research and development of inorganic nonmetallic materials in detail, and mainly introduces the application of 3DP, SLS and SLM in the field of ceramic and sand casting and analyzes the factors that affect the performance of the material. The factors are material processing technology, 3D forming process and post-treatment process. Finally, the paper presents the prospect of the material additive manufacturing of the gem material which is an important branch of inorganic nonmetallic materials.

Through the research and development of inorganic nonmetallic materials in recent years, the additive manufacturing process of inorganic nonmetallic materials has been developed rapidly, and some inorganic nonmetallic parts have been widely used, such as sand, sand core and a specific shape of gypsum. For materials such as ceramics and other products, although their performance has been improved, their density, compressive strength and dimensional accuracy are still not meet the needs of specific applications, so the material processing technology, threedimensional forming process, post-processing technology need a further study.

Table 3. Effect of PI (13 MPa),WIP $\left(64 \mathrm{MPa} / 135^{\circ} \mathrm{C}\right)$ and sintering on the density of parts [34]

\begin{tabular}{|c|c|c|c|c|}
\hline Process & SLS density, $\mathrm{g} / \mathrm{cm}^{3}(\%)$ & PI density, $\mathrm{g} / \mathrm{cm}^{3}(\%)$ & WIP density, $\mathrm{g} / \mathrm{cm}^{3}(\%)$ & Sintered density, $\mathrm{g} / \mathrm{cm}^{3}(\%)$ \\
\hline Sintering & \multirow{4}{*}{$0.78 \quad(37)$} & 1 & 1 & $1.50(39)$ \\
\hline Sintering+PI & & $1.45(54)$ & I & $2.50(64)$ \\
\hline WIP+sintering & & I & $1.96(93)$ & $3.51(89)$ \\
\hline $\mathrm{PI}+\mathrm{WIP}+$ sintering & & $1.45(54)$ & $2.24(83)$ & $3.43(88)$ \\
\hline
\end{tabular}


On the trend, the focus of the research of inorganic non-metallic materials in the future will be focused on improving the surface quality and overall mechanical properties, the specific improvements are as follows:

1. Develop a specific process for shaping material.

The material to be shaped is the most important source to determine the quality of the final piece and the performance of the material. The composition, composition ratio and particle size of the material to be shaped are important factors which affect the forming quality and performance. At present, the preparation of ceramic, coated sand has been commercialized, but manufacturers are fewer, especially the manufacture of forming ceramic materials. So it is the necessary to develop a variety of inorganic nonmetallic forming technology, and this necessity not only promotes the rapid formation of a wider range of inorganic nonmetallic materials, but also reduces the price of the product.

2. The specific inorganic non-metallic materials, threedimensional forming process to establish a specific mathematical model.

The quality, performance of final piece is effected by nozzle diameter, extrusion speed, extrusion pressure, scanning speed, layer thickness, the delay time, spreading a new layer, build orientation and other process parameters in 3DP and preheating temperature, laser power, scanning speed, scanning distance, scanning layer thickness and other process parameters in SLS, SLM. So far, the optimal threedimensional process parameters of forming one material are obtained by orthogonal experiment method, which makes the different materials to be formed obtain the optimal threedimensional process parameters by orthogonal experiment method. The experimental process is so cumbersome that the three-dimensional forming process parameters mathematical model, which fits the certain material are very urgent to be established.

3. In-depth study and broaden the post-processing process

Impregnation, isostatic pressing and high temperature sintering are the most commonly used post-treatment processes for the rapid formation of inorganic nonmetallic materials. Optimizing these process parameters can further improve the density and mechanical properties of forming green bodies. For the isostatic pressing process, the complex shape of the body is easy to deformation under sharp edges and corners in the process of pressurization and densification. In order to reduce its deformation, the blank package should be designed to match the body. Pressurize the body surface with the blank package covered. In addition, the three kinds of post-treatment processes infiltration, isostatic pressing and high temperature sintering are often time-consuming and increase the forming time of parts which is not conducive to mass production. It is necessary to explore more efficient and feasible treatment process to overcome this problem.

\section{Acknowledgments}

This work was supported by the National Natural Science Foundation of China No. 61272389 and the Fundamental Research Funds for the Zhejiang Institute of Geology and Mineral Resources No. 2014330101001736.
This work was also supported by the Priority project, the key science and technology project of Zhejiang province No. 2015C10135.

Yun YU and YongHui MA are Co-first author.

\section{REFERENCES}

1. Jiaxin, L. Application and Development Trend of Inorganic Non-metallic Materials China Powder Industry 45 (05) 2014: pp. 4-6.

2. Moon, J., Caballero, A.C., Hozer, L., Chiang, Y.M., Cima, M.J. Fabrication of Functionally Graded Reaction Infiltrated SiC-Si Composite By Three-dimensional Printing (3DPTM) Process Materials Science and Engineering: A. $298(1-2)$ 2001: pp. 110-119. https://doi.org/10.1016/S0921-5093(00)01282-X

3. Moon, J., Grau, J.E., Knezevic, V. Ink-jet Printing of Binders for Ceramic Components Journal of the American Ceramic Society 85 (04) 2002: pp. 755-762. https://doi.org/10.1111/j.1151-2916.2002.tb00168.x

4. Song, Y.Q., Jia, H.J., Xu, J. Structural Ceramics and Their Superplasticity. Introduction of Structural Ceramics Acta Metallurgica Sinica 45 (1) 2009: pp. 1-5. https://doi.org/10.3321/j.issn:0412-1961.2009.01.001

5. Kai, L. Investigation on the Hybrid Technology of Lasersintering /Cold Isostatic Pressing About Ceramic Powder, PhD thesis, 2014: pp. $3-8$.

6. Melcher, R., Martins, S., Travitzky, N., Greil, P. Fabrication of Al2O3-based Composites by Indirect 3DPrinting Materials Letters 60 (4) 2006: pp. 572-575. https://doi.org/10.1016/j.matlet.2005.09.059

7. Yao, D.X., Gomes, C.M., Zeng, Y.P., Liang, D.L. Near Zero Shrinkage Porous $\mathrm{Al}_{2} \mathrm{O}_{3}$ Prepared Via 3D-printing and Reaction Bonding Materials Letters $147(05)$ 2015: pp. $116-118$ https://doi.org/10.1016/j.matlet.2015.02.037

8. Weng, Z.H., Zeng, Q.F., Xie, C.W. Porous Silicon Nitride Ceramics Prepared By 3D Printing and Reaction Sintering Materials Review 27 (04) 2013: pp. 5-7. https://doi.org/10.3969/j.issn.1005-023X.2013.08.002

9. Cappi, B., Özkol, E., Ebert, J., Telle, R. Direct Inkjet Printing of $\mathrm{Si}_{3} \mathrm{~N}_{4}$ : Characterization of Ink, Green Bodies and Microstructure Journal of the European Ceramic Society 28 (13) 2008: pp. 2625-2628. https://doi.org/10.1016/j.jeurceramsoc.2008.03.004

10. Mott, M., Evans, J.R.G. Zirconia/Alumina Functionally Graded Material Made By Ceramic Ink Jet Printing Materials Science and Engineering: A $271(1-2)$ 1999: pp. $344-352$. https://doi.org/10.1016/S0921-5093(99)00266-X

11. Feng, L.Y., Yin, X.W., Li, X.M. Si3N4-SiC Composite Ceramic Prepared By Three Dimensional Printing and Chemical Vapor Infiltration Aeronautical Manufacturing Technology 400 (04) 2012: pp. 62-65. https://doi.org/10.3969/j.issn.1671-833X.2012.04.011

12. Fu, Z., Schlier, L., Travitzky, N., Greil, P. ThreeDimensional Printing of SiSiC Lattice Truss Structures Materials Science and Engineering: A 560 (10) 2013: pp. $851-856$. https://doi.org/10.1016/j.msea.2012.09.107

13. Wang, S.J., Yang, Y.N., Yang, W.D., Xu, D., Zhai, L.. Evaluation of Methods of Direct Casting Mold Manufacturing Based on RP technology Mechanical Science and Technology for Aerospace Engineering $22(03)$ 2003: pp. $461-464$. 
https://doi.org/10.3321/j.issn:1003-8728.2003.03.039

14. Yang, W.D., Yan, Y.N., Xun, D., Xu, D. Study on The Morphology of Aggregate Unit in the Process of Patternless Casting Manufacturing China Mechanical Engineering 14 (05) 2003: pp. 23-26.

https://doi.org/10.3321/j.issn:1004-132X.2003.05.006

15. Yang, W.D., Tan, R.H., Yan, Y.N., Xu, A.P. The Development of Patternless Casting Anufacturing Machine Machine Tool \& Hydraulics 42 (07) 2005: pp. $42-44$. https://doi.org/10.3969/j.issn.1001-3881.2005.07.017

16. Yang, W.D., Liu, L.B., Yang, Y.N. Research of Process Parameters of PCM Technique Based on Fuzzy Technology Journal of Hebei University of Technology 36 (06) 2007: pp. $80-85$.

https://doi.org/10.3969/j.issn.1007-2373.2007.06.017

17. Jianhuai, T. Application Research of Rapid Precision Casting Technology Without Mold Foundry Technology 34 (12) 2013:pp. 1796-1798.

18. Zhaoxian, Gu. Research on Rapid Combined Forming Process of Casting, PhD thesis, 2012: pp. 12-14.

19. Fan, S.J., Xu, X., Chen, B. Research on Application of Magnesium Phosphate Cement in 3D Printing New Building Materials (01) 2015: pp. 1-4. https://doi.org/10.3969/j.issn.1001-702X.2015.01.001

20. Butscher, A., Bohner, M., Roth, C., Ernstberger, A. Printability of Calciumphosphate Powders for ThreeDimensional Printing of Tissue Engineering Scaffolds Acta Biomaterialia 8 (1) 2012: pp. 373-385.

https://doi.org/10.1016/j.actbio.2011.08.027

21. Butscher, A., Bohner, M., Doebelin, N., Galea, L. Moisture Based Three-dimensional Printing of Calcium Phosphate Structures for Scaffold Engineering Acta Biomaterialia 9 (2) 2013: pp. 5369-5378.

https://doi.org/10.1016/j.actbio.2012.10.009

22. Butscher, A., Bohner, M., Doebelin, N., Hofmann, S. New Depowdering-friendly Designs for Three-dimensional Printing of Calcium Phosphate Bone Substitutes Acta Biomaterialia 9 (11) 2013: pp. 9149-9158. https://doi.org/10.1016/j.actbio.2013.07.019

23. Zhang, J., Zhao, S., Zhu, Y., Huang, Y., Zhu, M. ThreeDimensional Printing of Strontium-containing Mesoporous Bioactive Glass Scaffolds for Bone Regeneration Acta Biomaterialia 10 (5) 2014: pp. 2269-2281. https://doi.org/10.1016/j.actbio.2014.01.001

24. Wang, Z.M., Liu, W. 3D Printing Technology and Its Application in the Field of Architecture China Concrete 67 (10) 2015:pp. 50-57. https://doi.org/10.3969/j.issn.1674-7011.2015.01.010

25. Fang, Z., Zhao, T.T. Laser Solidification and Powder Layered Manufacturing Technology Automobile Technology \& Material (08) 2010: pp. 41-45. https://doi.org/10.3969/j.issn.1003-8817.2010.08.009

26. Peelamedu, R., Badzian, A., Roy, R. Sintering of Zirconia Nanopowder by Microwave-laser Hybrid Process Communications of the American Ceramic 87 (09) 2010: pp. $1806-1809$. https://doi.org/10.1111/j.1551-2916.2004.01806.x

27. Deckers, J., Shahzad, K, Vleugels, J., Kruth, J.P. Isostatic Pressing Assisted Indirect Selective Laser Sintering of Alumina Components Rapid Prototyping Journal 18 (5) 2012: pp. 409-419.

https://doi.org/10.1108/13552541211250409

28. Goodridge, R.D., Wood, D.J., Ohtsuki, C., Dalgarno, K.W. Biological Evaluation of an Apatite-mullite
Glass-ceramic Produced Via Selective Laser sintering Acta Biomaterialia 3 (2) 2007: 221-231.

https://doi.org/10.1016/j.actbio.2006.10.005

29. Bertrand, P., Bayle, F., Combe, C., Goeuriot, P. Ceramic Components Manufacturing by Selective Laser Sintering Applied Surface Science 254 (4) 2007: pp. 989-992. https://doi.org/10.1016/j.apsusc.2007.08.085

30. Shahzad, K., Deckers, J., Boury, S., Neirinck, B., Kruth, J.P. Preparation and Indirect Selective Laser Sintering of Alumina/PA Microspheres Ceramics International 38 (2) 2012: pp. 1241-1247. https://doi.org/10.1016/j.ceramint.2011.08.055

31. Liu, K., Shi, Y.S., Li, C.H., Hao, L., Liu, J., Weo, Q.S. Indirect Selective Laser Sintering of Epoxy Resin- $\mathrm{Al}_{2} \mathrm{O}_{3}$ Ceramic Powders Combined With Cold Isostatic Pressing Ceramics International 40 (5) 2014: pp. 7099-7106. https://doi.org/10.1016/j.ceramint.2013.12.043

32. Tang, H.H., Chiu, M.L., Yen, H.C. Slurry-based Selective Laser Sintering of Polymer-coated Ceramic Powders to Fabricate High Strength Alumina Parts Journal of the European Ceramic Society 31 (8) 2011: pp. 1383-1388. https://doi.org/10.1016/j.jeurceramsoc.2011.02.020

33. Tang, H.H., Yen, H.C. Slurry-based Additive Manufacturing of Ceramic Parts by Selective Laser Burn-out Journal of the European Ceramic Society 35 (3) 2015:pp. 981-987. https://doi.org/10.1016/j.jeurceramsoc.2014.10.019

34. Shahzad, K., Deckers, J., Zhang, Z., Kruth, J.P., Vleugels, J. Additive Manufacturing of Zirconia Parts by Indirect Selective Laser Sintering Journal of the European Ceramic Society 34 (1) 2014: pp. 81-89. https://doi.org/10.1016/j.jeurceramsoc.2013.07.023

35. Ren, Y.S., Hua, G.R., Luo, H.X., Tian, Z.J., Huang, Y.H. Experimental Research of Bulk Fabrication of Nano-SiC ceramic Powder by Laser Sintering Laser Technology 30 (04) 2006: pp. 402-405. https://doi.org/10.3969/j.issn.1001-3806.2006.04.028

36. Xiong, H., Xiong, B., Yu, H., Zhao, J. Effects of Binders on Dimensional Accuracy and Mechanical Properties of SiC Particulates Preforms Fabricated by Selective Laser Sintering Composites Part B: Engineering 44 (1) 2013: pp. 480-483. https://doi.org/10.1016/j.compositesb.2012.04.003

37. Wang, W., Liu, Y.X., Shi, X.D., Sheng, Z., Yxj, F. Biomaterials Composite Process Experiments Based on Selective Laser Sintering Manufacturing Technology \& Machine Tool (10) 2012: pp. 21-24. https://doi.org/10.3969/j.issn.1005-2402.2012.10.008

38. Renold Elsen, $\mathbf{S}$, Ramesh, T. Shrinkage Characteristics Studies on Conventional Sintered Zirconia Toughened Alumina Using Computed Tomography Imaging Technique International Journal of Refractory Metals and Hard Materials 54 (01) 2016: pp. 383-394. https://doi.org/10.1016/j.ijrmhm.2015.09.008

39. Song, J.L., Li, Y.T., Deng, Q.L., Hu, D.J. Rapid Prototyping Manufacturing of Silica Sand Patterns Based on Selective Laser Sintering Journal of Materials Processing Technology 187-188 2007: pp. 614-618. https://doi.org/10.1016/j.jmatprotec.2006.11.108

40. Liu, F.R., Zhao, J.J., Zhang, Q., Hu, D.L., He, C., Chen, J.M. Processing and Characterizations of 2\%PF/Silica Sand Core-shell Composite Powders by Selective Laser Sintering with a Higher Transmittance Fiber Laser International Journal of Machine Tools and Manufacture 60 2012: pp. $52-58$. https://doi.org/10.1016/j.ijmachtools.2012.05.003 
41. Wen, S., Shen, Q., Wei, Q., Yan, C., Zhu, W. Material Optimization and Post-processing of Sand Moulds Manufactured by the Selective Laser Sintering of Bindercoated Al2O3 Sands Journal of Materials Processing Technology 225 2015: pp. 93-102.

https://doi.org/10.1016/j.jmatprotec.2015.05.028

42. Kolan, K.C.R., Leu, M.C., Hilmas, G.E. Effect of Material, Process Parameters, and Simulated Body Fluids on Mechanical Properties of 13-93 Bioactive Glass Porous Constructs Made by Selective Laser Sintering Journal of the Mechanical Behavior of Biomedical Materials 13 2012: pp. $14-24$.

https://doi.org/10.1016/j.jmbbm.2012.04.001

43. Shuai, C., Li, P., Liu, J., Peng, S. Optimization of TCP/HAP ratio for Better Properties of Calcium Phosphate Scaffold Via Selective Laser Sintering Materials Characterization 77 2013: pp. 23-31. https://doi.org/10.1016/j.matchar.2012.12.009

44. Doyle, H., Lohfeld, S., Mchugh, P. Evaluating the Effect of Increasing Ceramic Content on the Mechanical, Material Microstructure and Degradation of Selective Laser Sintered Polycaprolactone/ $\beta$-tricalcium Phosphate Materials Medical Engineering \& Physics 37 (8) 2015: pp. 767-776. https://doi.org/10.1016/j.medengphy.2015.05.009

45. Yin, H., Bai, P.K., Liu, B., Li, Y.X. Present Situation and Development Trend of Selective Laser Melting Technology for Metal Powder Hot Working Technology 39 (1) 2010: pp. $140-144$. https://doi.org/10.3969/j.issn.1001-3814.2010.01.045

46. Liu, W., Liu, T.T., Liao, W.H., Zhang, K. Study and Application of Selective Laser Sintering /Melting Technology of Ceramic Materials Bulletin of the Chinese Ceramic Society 33 (11) 2014: pp. 2881-2890. https://doi.org/10.16552/j.cnki.issn1001-1625.2014.11.017

47. Chang, F., Gu, D., Dai, D., Yuan, P. Selective Laser Melting of In-situ Al4SiC4+SiC Hybrid Reinforced Al Matrix Composites: Influence of Starting SiC Particle Size Surface and Coatings Technology 272 2015: pp. 15-24. https://doi.org/10.1016/j.surfcoat.2015.04.029

48. Shishkovsky, I., Yadroitsev, I., Bertrand, P., Smurov, I. Alumina-zirconium Ceramics Synthesis by Selective Laser Sintering/Melting Applied Surface Science 254 (4) 2007: pp. $966-970$. https://doi.org/10.1016/j.apsusc.2007.09.001

49. Yves-Christian, H., Jan, W., Wilhelm, M., Konrad, W., Reinhart, P. Net Shaped High Performance Oxide Ceramic Parts by Selective Laser Melting Physics Procedia 5 (2) 2010: pp. 587-594 https://doi.org/10.1016/j.phpro.2010.08.086

50. Fateri, M., Gebhardt, A., Thuemmler, S., Thurn, L. Experimental Investigation on Selective Laser Melting of Glass Physics Procedia 56 2014: pp 357-364. https://doi.org/10.1016/j.phpro.2014.08.118

51. Liu, Q., Danlos, Y., Song, B., Zhang, B., Yin, S., Liao, H. Effect of High-temperature Preheating on the Selective Laser Melting of Yttria-stabilized Zirconia Ceramic Journal of Materials Processing Technology 222 2015: pp. 61-74. https://doi.org/10.1016/j.jmatprotec.2015.02.036

52. Wei, Q., Li, S., Han, C., Li, W., Chen, L.Y. Selective Laser Melting of Stainless-steel/Nano-hydroxyapatite Composites for Medical Applications: Microstructure, Element Distribution, Crack and Mechanical Properties Journal of Materials Processing Technology 222 2015: pp. 444-453. https://doi.org/10.1016/j.jmatprotec.2015.02.010
53. Zeng, L., Xiang, N., Wei, B. A Comparison of Corrosion Resistance of Cobalt-chromium-molybdenum Metal Ceramic Alloy Fabricated with Selective Laser Melting and Traditional Processing Journal Prosthetic Dentistry 112 (5) 2014: pp. $1217-1224$. https://doi.org/10.1016/j.prosdent.2014.03.018

54. Zocca, A., Gomes, C.M., Bernardo, E., Müller, R., Günster, J. LAS Glass-ceramic Scaffolds by ThreeDimensional Printing Journal of the European Ceramic Society 33 (9) 2013: pp. $1525-1533$.

https://doi.org/10.1016/j.jeurceramsoc.2012.12.012

55. Barinov, S.M, Vakhrushev, I.V, Komlev, V.S, Mironov, A.V. 3D Printing of Ceramic Scaffolds for Engineering of Bone Tissue Inorganic Materials: Applied Research 6 (4) 2015: pp. 316-322. https://doi.org/10.1134/S207511331504005X

56. Di, S., Liu, K., Zhang, X., Liao, H., Chen, X. Applications of Three-dimensional Printing Technology in the Cardiovascular Field Internal and Emergency Medicine 10(7) 2015: pp. 769-780. https://doi.org/10.1007/s11739-015-1282-9

57. Davydova, A., Domashenkov, A., Sova, A., Movtchan, I. Selective Laser Melting of Boron Carbide Particles Coated by a Cobalt-based Metal Layer Journal of Materials Processing Technology 229 2016: pp. 361-366. https://doi.org/10.1016/j.jmatprotec.2015.09.033

58. Zhou, Q., Gao, Y., Liu, K., Xue, L., Yan, Y. Fabrication of Li2TiO3 Pebbles by a Selective Laser Sintering Process Fusion Engineering and Design 100 2015: pp. 166-170. https://doi.org/10.1016/j.fusengdes.2015.05.061

59. Ruys, A., Gingu, O. Powder Processing of Bulk Components in Manufacturing Handbook of Manufacturing Engineering and Technology 2014: pp.487-556. https://doi.org./10.1007/978-1-4471-4670-4_48

60. Song, J.H., Nur, H.M. Defects and Prevention in Ceramic Components Fabricated by Inkjet Printing Journal of Materials Processing Technology 155-156 2004: pp. $1286-1292$. https://doi.org/10.1016/j.jmatprotec.2004.04.292

61. Tang, C.C., Yu, H.Y., Qiao, L., Dong, X.T., Chen, S.L. Preparation and Molding of $\mathrm{Al}_{2} \mathrm{O}_{3} / \mathrm{PA} 12$ Composite Used in the Selective Laser Sintering China Plastics Industry 43 (02) 2015: pp. 130-135. https://doi.org/10.3969/j.issn.1005-5770.2015.02.031

62. Shi, Y.S., Yan, C.Z., Wei, Q.S. Selective Laser Sintering Polymer Material Scientia Sinica Informationis 45 (02) 2015: pp. $204-211$. https://doi.org/10.1360/N112014-00222

63. Wu, Y., Du, J., Choy, K., Hench, L.L. Fabrication of Titanium Dioxide Ceramics by Laser Sintering Green Layers Prepared Via Aerosol Assisted Spray Deposition Materials Science and Engineering: A 454-455 2007: pp. 148-155. https://doi.org/10.1016/j.msea.2006.11.077

64. Singh, S., Sharma, V.S., Sachdeva, A. Progress in Selective Laser Sintering Using Metallic Powders: A Review Materials Science \& Technology 8 (32) 2016: pp. $760-772$. https://doi.org/10.1179/1743284715Y.0000000136

65. Sun, C., Tian, X., Wang, L., Liu, Y., Günster, J., Wirth, C.M. Effect of Particle Size Gradation on the Performance of Ceramic 3d Printing Process Ceramics International 43 (1) 2017: pp. 578-584. https://doi.org/10.1016/j.ceramint.2016.09.197

66. Kietzmann, J., Pitt, L., Berthon, P. Disruptions, Decisions, and Destinations: Enter the Age of 3-D Printing and Additive 
Manufacturing Business Horizons $58(2)$

2015: pp. 209-215.

https://doi.org/10.1016/j.bushor.2014.11.005

67. Gaytan, S.M., Cadena, M.A., Karim, H. Fabrication of Barium Titanate by Binder Jetting Additive Manufacturing Technology Ceramics International 41 (5) 2015: pp. $6610-6619$.

https://doi.org/10.1016/j.ceramint.2015.01.108

68. Cao, S., Wei, X., Sun, Z., Zhang, H.H. Investigation on Urea-formaldehyde Resin As an In-powder Adhesive for the Fabrication of Al2O3/Borosilicate-glass Composite Parts by Three Dimensional Printing (3DP) Journal of Materials Processing Technology 217 2015: pp. 241-252. https://doi.org/10.1016/j.jmatprotec.2014.11.021

69. Liu, J.Y., Wu, M.L., Cai, J., Chen, J., Xie, F. Influence of Operating Parameters on 3D Printing Ceramic Parts Journal of Shanghai University of Electric Power $31(04)$ 2015: pp. 376-380. https://doi.org/10.3969/j.issn.1006-4729.2015.04.014

70. Asadi-Eydivand, M., Solati-Hashjin, M., Farzad, A., Osman, N.A.A. Effect of Technical Parameters on Porous Structure and Strength of 3D Printed Calcium Sulfate Prototypes Robotics and Computer-Integrated Manufacturing 37 2016: pp. 57-67. https://doi.org/10.1016/j.rcim.2015.06.005

71. Ramakrishnan, N., Rajesh, P.K., Ponnambalam, P., Prakasan, K. Studies on Peparation of Ceramic Inks and Simulation of Drop Formation and Spread in Direct Ceramic Inkjet Printing Journal of Materials Processing Technology 169 (3) 2005: pp. 372-381.

https://doi.org/10.1016/j.jmatprotec.2005.03.021

72. Kotz, F., Arnold, K., Bauer, W., Schild, D., Keller, N., Sachsenheimer, K. Three-dimensional Printing of Transparent Fused Silica Glass Nature 544 (7650) 2017: pp. 337-339. http://doi.org/10.1038/nature22061

73. Calignano, F., Manfredi, D., Ambrosio, E.P., Iuliano, L., Fino, P. Influence of Process Parameters on Surface Roughness of Aluminum Parts Produced by DMLS The International Journal of Advanced Manufacturing Technology 67 (9-12) 2013: pp. 2743-2751. https://doi.org/10.1007/s00170-012-4688-9

74. Basile, N., Gonon, M., Petit, F., Cambier, F. Processing of a Glass Ceramic Surface by Selective Focused Beam Laser Treatment Ceramics International $42(01)$ 2015: pp. $1720-1727$. https://doi.org/10.1016/j.ceramint.2015.09.129

75. Wang, Z., Shi, Y., He, W., Liu, K., Zhang, Y. Compound Process of Selectivelaser Processed Alumina Parts Densified by Cold Isostatic Pressing and Solid State Sintering: Experiments, Full Process Simulation and Parameter Optimization Ceramics International 41 (2) 2015: pp. $3245-3253$.

https://doi.org/10.1016/j.ceramint.2014.11.014
76. Deckers, J., Meyers, S., Kruth, J.P., Vleugels, J. Direct Selective Laser Sintering/Melting of High Density Alumina Powder Layers at Elevated Temperatures Physics Procedia 56 2014: pp. $117-124$.

https://doi.org/10.1016/j.phpro.2014.08.154

77. Wang, W., Wang, X.L., Dong, M. Study About the Warping Distortion of Selective Laser Sintering Rapid Prototyping Workpiece Manufacturing Technology \& Machine Tool (04) 2010: pp. $127-129$. https://doi.org/10.3969/j.issn.1005-2402.2010.04.041

78. Raghunath, N., Pandey, P.M. Improving Accuracy Through Shrinkage Modelling by Using Taguchi Method in Selective Laser Sintering International Journal of Machine Tools and Manufacture 47 (6) 2007: pp. 985 - 995. https://doi.org/10.1016/j.ijmachtools.2006.07.001

79. Liu, K., Shi, Y., He, W., Li, C. Wei, Q. Densification of Alumina Components Via Indirect Selective Laser Sintering Combined with Isostatic Pressing The International Journal of Advanced Manufacturing Technology $67(9-12)$ 2013: pp. 2511-2519. https://doi.org/10.1007/s00170-012-4668-0

80. Cheng, D. Study on Selective Laser Sintering of Aumina Parts and Post Pocess PhD thesis 2007: pp. 73.

81. Sing, S.L., Yeong, W.Y., Wiria, F.E., Tay, B.Y., Zhao, Z., Zhao, L. Direct Selective Laser Sintering and Melting of Ceramics: A Review Rapid Prototyping Journal 23 (3) 2017: pp. $611-623$. https://doi.org/10.1108/RPJ-11-2015-0178

82. Warnakula, A., Singamneni, S. Selective Laser Sintering of Nano $\mathrm{Al}_{2} \mathrm{O}_{3}$ Infused Polyamide $10(8) \quad$ Materials 2017: pp. $864-882$. https://doi.org/10.3390/ma10080864

83. Kumar, N., Kumar, H., Khurmi, J.S. Experimental Investigation of Process Parameters for Rapid Prototyping Technique (Selective Laser Sintering) to Enhance the Part Quality of Prototype by Taguchi Method Procedia Technology 23 2016: pp. 352-360. https://doi.org/10.1016/j.protcy.2016.03.037

84. Kumar, N., Kumar, H., Khurmi, J.S. Experimental Investigation of Process Parameters for Rapid Prototyping Technique (Selective Laser Sintering) to Enhance the Part Quality of Prototype by Taguchi Method Procedia Technology 23 2016: pp. 352-360. https://doi.org/10.1016/j.protcy.2016.03.037

85. Lu, Y., Zhang, H., Li, H., Xu, H., Huang, G., Qin, Z. Crystallization Prediction on Laser Three-dimensional Printing of Zr-based Bulk Metallic Glass Journal of NonCrystalline Solid 461 2017: pp. 12-17. https://doi.org/10.1016/j.jnoncrysol.2017.01.038

86. Shahzad, K., Deckers, J., Kruth, J., Vleugels, J. Additive Manufacturing of Alumina Parts by Indirect Selective Laser Sintering and Post Processing Journal of Materials Processing Technology 213 (9) 2013: pp. 1484-1494. https://doi.org/10.1016/j.jmatprotec.2013.03.014 